Currículo sem Fronteiras, v. 19, n. 3, p. 1188-1201, set./dez. 2019

\title{
PESQUISAS, POLÍTICAS E PRÁTICAS NO ÂMBITO DA EDUCAÇÃO INCLUSIVA: pistas e problematizações
}

\author{
Edna Castro de Oliveira \\ Universidade Federal do Espírito Santo \\ Marcia Roxana Cruces Cuevas \\ Universidade Federal do Espírito Santo
}

\begin{abstract}
Resumo
A dimensão política das práticas e políticas públicas de inclusão nos últimos vinte anos no Brasil é analisada colaborativamente ao movimento da Educação Inclusiva (EI) no Oeste Europeu e nos Estados Unidos, a partir de questões suscitadas pelas pesquisas do campo naquele contexto, que constituem objeto das reflexões levantadas pelo texto de Alfredo Artiles “Que Inclusão e diversidade na educação”, que compõe este dossiê. Assumimos a perspectiva epistemológica da abordagem pluralista do campo das políticas públicas, tendo em vista a complexidade que compõe as políticas de inclusão. Com base em pesquisa documental, exploramos produções de autores nacionais e documentos legais no campo das políticas públicas de educação especial na perspectiva da inclusão no Brasil, bem como uma pesquisa em estado da arte de Guimarães (2014), em nível de doutorado do Programa de Pós-Graduação em Educação/UFES. As análises colocam em evidência a aproximação com a constatação de Artiles em torno da produção daltônica das pesquisas, confirmando a necessidade de ampliar o trabalho da investigação para atravessamentos de gênero, etnia, sexualidade presentes na diversidade de contextos e histórias de vida dos sujeitos da educação de jovens e adultos (EJA).
\end{abstract}

Palavras-chave: Educação de Jovens e Adultos; Educação Especial; Educação Inclusiva.

\begin{abstract}
The political aspect of the practices and public inclusive policies in the last 20 years in Brazil is analyzed as well as the Inclusive Education (IE) movement in the Western Europe and the United States. The issues raised by the results of field research in that context, by Alfredo Artiles' text "What kind of inclusion and diversity in education?" that is part of this dossier, serves as this study's start point. This study has an epistemological perspective of the pluralist approach in the public policies field, considering the complexity of the inclusive policies. Based on the documentary research on the topic at a national scale, legal documents and on thesis and dissertations of UFES Graduate School of Education, we analyzed the public policies on the light of the studies carried out in the state of ES related to inclusive matters. The analysis confirm Artiles' findings concerning the limits of the research, reassuring the need to broaden the scope of the researches on the area in order to include the discussion on gender, ethnicity and sexuality present in the contexts and life stories of the Youth and Adult Education subjects that we have been accompanying .
\end{abstract}

Keywords: Youth and Adult Education; Special Education; Inclusive Education. 


\section{Introdução}

Em tempos de naturalização do discurso da inclusão produzido no contexto de indução de políticas públicas globais, como mecanismo para o necessário e permanente processo de gestão de novas desigualdades, o texto de Alfredo Artiles (2018), intitulado "Que inclusão e diversidade na educação”, oferece-nos elementos para reflexão sobre as questões por ele levantadas, a partir da produção das pesquisas sobre educação inclusiva (EI) a que se remete, no âmbito dos Estados Unidos e Oeste Europeu. Dessa forma, à luz das contribuições de Artiles, o artigo tem por objetivo problematizar a dimensão política das práticas e políticas públicas de inclusão presentes nas pesquisas realizadas no estado do Espírito Santo/Brasil, nos últimos vinte anos no contexto das políticas de Educação de Jovens e Adultos e de Educação Especial na perspectiva da inclusão.

Dentre as problematizações apresentadas no texto que compõe este Dossiê, tomaremos algumas para reflexão, em relação direta com estudos sobre a temática realizados no Brasil, em especial Bueno (2001), Veiga-Neto e Lopes (2011), Lopes (2007), Padilha; Oliveira (2013), Diniz (2007), Moraes e Kastrup (2010) e Guimarães (2014), sobre Inclusão, Educação Inclusiva e estudos da deficiência. As questões levantadas por autores brasileiros nos permitem debater os argumentos apresentados e ampliar outras referências que, nos limites do texto, somos chamadas a contextualizar. Referimo-nos à inserção no debate da Educação Inclusiva/EI, promovido pelo autor em foco, da menção às pessoas jovens e adultas com deficiência que, no contexto brasileiro ${ }^{1}$, vêm cada vez mais saindo da invisibilidade e buscando o acesso à escola, ao passo em que desafiam as políticas e as práticas de inclusão nas suas diferentes facetas.

A opção por pautar os últimos vinte anos remete à possibilidade de considerar o mesmo período histórico a que se refere Artiles (2018) nas pesquisas mencionadas, o que instiga a situar em quê e o que, "supostamente", avançamos no âmbito das políticas e práticas de inclusão, em tempos de vigência de políticas neoliberais. Dessa forma, somos provocadas pelo autor a refletir, desde dentro, sobre as apropriações feitas da perspectiva da Educação Inclusiva no Brasil, expressas nas produções acadêmicas locais que têm se debruçado sobre a análise da efetividade das políticas inclusivas. É importante demarcar esta posição, uma vez que, segundo o autor, “[...] poucos esforços foram feitos para se entender como a EI está apropriada e contextualizada em nações do sul e o que se pode aprender a partir de suas experiências para a teoria e prática da EI” (Ibid., p. 3).

Compreendemos as políticas públicas de inclusão como práticas que se fabricam no plural e que, como Foucault (2005) nos mostra, são constituídas com a noção do Estado Moderno, fabricando novas experiências, práticas, que passaram e passam a definir os espaços, campos de saberes, as instituições e os próprios sujeitos dessas instituições e políticas em curso. Assim, o conceito de prática com que trabalhamos indica para as regras, normas que atravessam o corpo e as atividades dos homens, fabricando-os. Desse modo, seguindo a orientação foucaultiana, tratamos os discursos "como práticas que formam 
sistematicamente os objetos de que falam” (Ibid., p. 54), não existindo independência entre estas e o sistema discursivo.

Ao nos voltarmos às políticas e práticas da EI no Brasil, reconhecemos a amplitude de avanços, o enfrentamento a desafios e a colaboração na própria constituição dos sujeitos, como os da educação de jovens e adultos, ora in/excluídos da atenção das políticas públicas. Ou seja, como afirmado por Lasta e Hillesheim (2012), a EI aqui será trabalhada como uma política pública do Estado Moderno importante no horizonte e no tensionamento das forças produtivas, mas que, processualmente, também é questionada pela realidade que afirma.

O fomento de iniciativas de políticas de inclusão nas mais variadas esferas da prática social, em especial no campo da educação, com ênfase em crianças e jovens, a partir do dispositivo da Declaração de Salamanca (BRASIL, 2003) faz ganhar corpo a contestação de Artiles (2018, p. 3) de que "iniciativas europeias e norte-americanas exportaram a EI para nações com condições socioeconômicas e históricas diametricamente diferentes, com pouca atenção a adaptações e às dinâmicas culturais”. Marcada na sua gênese pela busca da justiça social e de educação para todos, a exportação da ideia da EI, disseminada pelo acordo de Salamanca (op. cit., 2003), merece atenção nas reflexões aqui pautadas.

Reconhecemos como em Lasta e Hillesheim (2012) e Lopes (2007) que as políticas inclusivistas marcam as práticas pedagógicas modernas, afirmando um ideário revolucionário e pretensionista na medida em que exigem conhecimento dos sujeitos da aprendizagem. Assim, a inclusão e suas práticas, segundo autoras acima, constituem-se em uma metanarrativa ${ }^{2}$.

No que se refere a sua apropriação pelo contexto brasileiro, temos que considerar, conforme Bueno (2001), o que se produziu de mudança na tradução do texto original da Declaração referida, e na indução das políticas de EI pelo Ministério da Educação. Ou seja, a substituição da ênfase da integração pela da inclusão.

Algumas ponderações de Artiles (2018) sobre a restrição da EI à Educação Especial, nos Estados Unidos, dialogam com Bueno (2001), Padilha e Oliveira (2013) no nosso contexto quando insistem em ressaltar, com análises distintas, as razões pelas quais "de modo geral, o debate sobre a inclusão tem incidido principalmente na área de Educação Especial” (OLIVEIRA; PADILHA, 2013, p. 18).

Como vozes de dentro, de pesquisadores do campo da Educação Especial no Brasil, as autoras destacam a importância de se ampliar a concepção de inclusão social e inclusão escolar, não restringindo-a à Educação Especial, muito menos limitando o seu debate "ao estudo das políticas afirmativas que objetivam eliminar desigualdades históricas. Afirmam a importância de se conceber a educação escolar como parte de um projeto de sociedade, construído pelos sujeitos [...]” (Ibid., p. 18).

Esta compreensão, no Brasil, caracteriza uma opção de estudos que prioriza os aspectos sócio--históricos e culturais demarcando, desta forma, diferenças na maneira como as pesquisas, principalmente nos Estados Unidos, têm se caracterizado de acordo com Artiles (2018). A postura daltônica das pesquisas no contexto em foco considera irrelevante "as condições socioculturais e históricas e experiências dos indivíduos [e suas comunidades] no 
estudo da EI” (Ibid., p. 2). Essa postura ignora, ainda, segundo a literatura, “as interseções de gênero, raça, classe social, idioma e assim por diante” (Ibid., p. 2).

Nesse sentido, as interlocuções com a produção da pesquisa brasileira podem nos ajudar a aferir diferenças nas abordagens da EI, em diálogo com o que nos interpelam as ênfases das pesquisas mencionadas por Artiles (2018). Segundo ele, a EI está se tornando cada vez mais invisível, particularmente em países com altos níveis de desenvolvimento econômico, constituindo-se em uma das forças que têm produzido o estreitamento da EI nos Estados Unidos à suposição de que esta seja "uma ideia universal, dispensando o papel dos contextos sócio-histórico e culturais. Talvez seja esta uma das principais diferenças a considerar no debate sobre o que tem sido denominado paradigma de inclusão. Se a EI tende a se tornar invisível nos países com alto nível de desenvolvimento, o que podemos ter como horizonte num país como o Brasil, em que as desigualdades históricas tendem a explorar e condenar ao confinamento “ [...] os povos negros e indígenas, analfabetos, os deficientes, os velhos, os loucos, os diferentes” (PADILHA; OLIVEIRA, 2013, p. 18), população que tem sido excluída do direito ao acesso ao conhecimento científico, tecnológico, cultural e artístico que todos somos chamados a compartilhar como produção da humanidade? Em quê avançamos, uma vez que, concordando com Bueno (2001), o horizonte da sociedade democrática tornase cada vez mais distante e, não sem razões, que são políticas, têm dado lugar ao discurso da sociedade inclusiva e da educação inclusiva?

Do ponto de vista teórico-metodológico, a pesquisa se orientou por uma análise documental, com revisão de literatura das epistemologias das políticas públicas expressas em documento norteador das políticas de inclusão no País, bem como pelas contribuições de produções nacionais e de uma pesquisa em estado da arte, de Guimarães (2014), em nível de doutorado do Programa de Pós-Graduação em Educação/UFES, com o objetivo de colaborar na identificação das lacunas existentes nesse contexto (MAINARDES, 2018).

Segundo Cellard (2008), a pesquisa documental envolve uma análise preliminar e observa em sua construção elementos como o contexto, a autenticidade, a natureza, os autores e os conceitos centrais por eles usados e, finalmente, a coerência interna do texto. Considerando estes delineamentos, pautamos nosso trabalho por uma análise preliminar de produções dos autores anteriormente mencionados (Bueno (2001), Veiga-Neto e Lopes (2011), Lopes (2007), Padilha e Oliveira (2013), Diniz (2007), Moraes e Kastrup (2010) e Guimarães (2014) e, na sequência, o seguinte documento: versão da tradução da Declaração de Salamanca, realizada pela Coordenadoria Nacional para a Integração da Pessoa Portadora de Deficiência (CORDE), publicada em 1994 e reeditada em 1997.

De forma coerente com a opção epistemológica, assumimos a abordagem pluralista do campo das políticas educativas. Esta abordagem, de acordo com Mainardes (2018), guarda suas possibilidades e limites e caracteriza-se pela combinação de perspectivas teóricas distintas, ou "teorização combinada como um esforço de articular teorias ou conceitos oriundos de diferentes aportes, com o objetivo de compor um quadro teórico consistente para fundamentar determinada análise” (Ibid., p. 6), na busca de compreensão do objeto. No tensionamento dos diferentes pontos de vista que confluem em pontos comuns, situamos a 
contribuição deste debate para a produção de conhecimento neste campo de estudos, na perspectiva de fazer avançar a discussão nas práticas e nas “políticas de inclusão”.

As ponderações acima nos levam a organizar este texto em duas partes. Em um primeiro momento, pautamos reflexões sobre a EI e a ambiguidade deste conceito, tal como explorado por Artiles (2018). Busca-se, na sequência, explorar a produção das pesquisas compiladas na tese de Guimarães (2014) como estado da arte, no campo da Educação Especial, oriundas do Programa de Pós-Graduação em Educação da Universidade Federal do Espírito Santo, em especial. Ao final, ensaiamos algumas provisórias conclusões, ante a complexidade que envolve o tema e o desafio de ampliar o debater das provocações instigadas.

\section{0 discurso da Educação Inclusiva ou "exclusões includentes"}

Não se pode negar os avanços obtidos no âmbito educacional, no caso brasileiro, quando o que está em questão remete às políticas de inclusão. Mesmo sem pretensão de uma análise comparativa, não podemos deixar de tecer considerações sobre convergências e estranhamentos de autores brasileiros com as inquietações expressas por Artiles (2018), quando reflete sobre a sua própria postura crítica acerca da inclusão e o sentido que a mesma possa assumir aos olhos dos seus pares, sem que seja visto como alguém contrário a essa ênfase.

No contexto abordado pelo autor observa-se, segundo ele, "um estreitamento da noção de educação inclusiva que leva a um foco quase exclusivo na incapacidade” (ARTILES, 2018, p 1). Esta observação que, inicia a reflexão proposta por ele, também é destacada nos estudos sobre a deficiência desenvolvidos na região sudeste no Brasil, que assumem subverter concepções essencialistas de deficiência que a tem atrelado, apenas, ao paradigma biomédico em detrimento da perspectiva social (MORAES; KASTRUP, 2010).

O modelo acima mencionado entende a deficiência como consequência advinda de uma lesão em órgão do corpo, sendo a pessoa com deficiência alvo e objeto de cuidados biomédicos (DINIZ, 2007). Já o modelo social de deficiência aborda esta questão desde uma perspectiva mais complexa, colocando as condições de vida e a própria estrutura social como elementos constituintes no modo como nos relacionamos com a deficiência. Este enfoque vem-se constituindo desde 2001 nos diversos países do Sul e na América do Norte e Europa, lugares em que diversos movimentos sociais ${ }^{3}$ têm reivindicado a igualdade e equidade de oportunidades e direitos para pessoas com deficiência ${ }^{4}$.

Ainda, quando levamos em consideração a argumentação de Artiles (2018) a respeito das dificuldades para a expansão e refinamento da EI, segundo ele, encontramo-las em três forças, sendo uma delas a "natureza daltônica das pesquisas” (Ibid., p. 1), o que nos leva à busca de ampliação do sentido que o autor atribui à sua argumentação.

Segundo o dicionário Priberam da Língua Portuguesa (2014) o daltonismo corresponderia a uma anomalia da visão que interfere na identificação e percepção das cores. Nesse sentido, a colocação de Artiles (2018) aponta para um olhar crítico a respeito da 
própria produção acadêmica que, entendemos, na visão do autor, sofreria de uma anomalia no modo como se olha para os fenômenos estudados.

Esta crítica a encontramos também em pesquisadores brasileiros que se negam a produzir investigações que, apenas, reproduzam a realidade e relações e que assumem o modelo da autoprodução do sistema cognitivo de Varela (VARELA; THOMPSON; ROSCH, 1992) na realização de trabalhos de investigação que intervêm, criando problemas de forma ativa (MORAES; KASTRUP, 2010).

Da mesma forma, vemos no Brasil a proliferação de pesquisas e trabalhos que operam com diversos paradigmas que assumem a ação como central na construção de suas contribuições. Existem trabalhos orientados pelas perspectivas crítico-culturais e pósestruturais. De modo amplo, podemos afirmar que existem produções com várias leituras acerca da compreensão da Educação Inclusiva que tencionam a produção do campo internamente e, por esta razão, acenam possibilidades de revisão crítica de suas bases teóricas, epistemológicas e ético-políticas.

Nesse mesmo contexto, um movimento oposto à ideia restritiva da EI à Educação Especial é afirmado com Veiga-Neto e Lopes (2011), onde podemos situar “[...] uma ampliação da noção de inclusão [que] passou a abarcar um amplo conjunto de práticas voltadas para todos aqueles que historicamente sofriam por discriminação negativa” (VEIGA-NETO; LOPES, 2011, p. 122). Os autores chamam nossa atenção para a urgência de questionar os usos da inclusão, uma vez que tem sido utilizada "para se referir a um número cada vez maior e mais diverso de indivíduos a incluir ou já incluídos”, aqueles que têm sido confinados a viverem "sob condições precárias e até de miserabilidade, bem como pessoas que sofrem discriminação negativa graças ao fato de terem ou assumirem determinadas identidades de gênero de raça/etnia etc” (Ibid., p. 122). Tal como o faz Artiles (2018) esses autores, ao problematizarem a inclusão, deixam também explícita a ideia de que isto não significa serem "contra as práticas e políticas que a inventam como uma necessidade de nosso tempo” (op. cit., p. 122) mas insistem em que, ao tecerem suas críticas, buscam "olhar outras coisas [...] pensar coisas ainda não pensadas sobre as práticas que a determinam e as políticas” (op. cit., p. 122).

Com essa forma de abordagem, Veiga-Neto; Lopes (2011) nos trazem para pensar, a partir da "crítica radical”, diferentes acepções de inclusão, o que nos faz retomar a pergunta de Artiles (2018), quando interroga sobre “Que Inclusão e que diversidade na educação?” O que implica compreender de que inclusão estamos falando? Com que concepção operamos?

Segundo Veiga-Neto e Lopes (2011) a inclusão pode ser entendida como um conjunto de práticas que subjetivam os indivíduos a olharem para si e para o outro, fundadas em uma divisão platônica das relações; também pode ser entendida como uma condição de vida em luta pelo direito de se autorrepresentar, participar de espaços públicos, ser contabilizado e atingido pelas políticas de Estado. [...] pode ser entendida como conjunto de práticas sociais, culturais, educacionais, de saúde, entre outras, voltadas para a população que se quer disciplinar, acompanhar e regulamentar (Ibid., p. 123).

As várias acepções de Inclusão pautadas pelos autores nos levam a remeter o foco da pergunta sobre “que inclusão”, levantada por Artiles (2018), para as pessoas jovens e adultas 
com deficiência no contexto brasileiro, uma vez que encontramos semelhanças nas práticas referidas pelo autor com estudantes das minorias estadunidenses. Segundo ele, "estudantes afro-americanos e nativo-americanos são os mais afetados pelas chamadas categorias de deficiência subjetiva a nível nacional” (Ibid., p. 3). A natureza daltônica da pesquisa nos EUA, de acordo com ele, ignora "as interseções de classe social, gênero, raça e idioma" (Ibid., p. 2).

À luz desta reflexão, quando nos voltamos para os estudos aqui pautados no contexto brasileiro, configura-se a hipótese de que, embora se esteja alerta para as interseções mencionadas, a categoria da deficiência subjetiva, tal como referida por Artiles (2018), embora careça de ser estudada, parece ser o que impulsiona a chegada de jovens e adultos das camadas populares, rotulados atualmente como "público alvo da Educação Especial" para a EJA. Como vimos, não podemos ignorar o que "as atuais políticas e práticas inclusivas representam para o avanço nos direitos das pessoas e nas condições de vida mais igualitárias” (VEIGA-NETO; LOPES, 2011, p. 132).

No entanto, haveremos de estar atentas para o que realmente essas práticas significam quando lidamos com pessoas jovens e adultas, em especial mulheres, marcadas pela “dimensão subjetiva da deficiência”. Arriscamos pensar que a concepção de EI que se volta “para a população que se quer disciplinar, acompanhar e regulamentar” (Ibid., 2011, p. 123), acaba por forjar, nos espaços de inclusão escolar e não escolar, subjetividades "com deficiência”, tecidas na negação da dignidade humana, no silenciamento, na invisibilidade da existência, no sofrimento psicológico. As “exclusões includentes” (ARTILES, 2018, p. 4), mencionadas por Artiles (Ibid.), nos permitem reiterar a questão: Que inclusão de pessoas jovens e adultas com deficiência vem sendo promovida e pesquisada no Brasil, uma vez que, como já vimos, não podemos ignorar as mudanças, mesmo que mínimas de acesso desta população às políticas de inclusão colocadas aqui em questão?

As reflexões até então feitas reafirmam a ambivalência do conceito de EI e nos alertam para a importância de rever a orientação das práticas que vêm ganhando corpo na formulação das políticas, com vários desafios à produção da pesquisa.

\section{Contribuições das pesquisas locais no âmbito da Educação Inclusiva}

Guimarães (2014), em seu estudo bibliográfico, buscou construir uma hermenêutica das produções de teses e dissertações defendidas no Programa de Pós-Graduação em Educação da Universidade Federal do Espírito Santo, para buscar compreender e mapear os movimentos que vêm acontecendo no cotidiano das escolas de ensino comum do estado, a partir da Educação Especial numa perspectiva inclusiva. Trabalhou com trinta e sete pesquisas, entre as quais havia trinta e três (33) dissertações de mestrado e quatro (4) teses de doutorado, produzidas entre os anos 2000 a 2010, a partir da linha de "Diversidade e práticas educacionais inclusivas” no âmbito do PPGE-UFES.

Na tese de Guimarães (2014) encontramos contribuições importantes para nossa reflexão, já que se trata de uma pesquisa que contribui com uma reflexão dos saberes e fazeres 
que são evidenciados nas diferentes pesquisas que tratam da inclusão de pessoas deficientes em escolas regulares no estado do estado do Espírito Santo.

Entre suas principais contribuições destacamos o olhar ambíguo e paradoxal que apresenta das contribuições das pesquisas que, como ele destaca, acabam "revelando uma profunda crise de um modelo de racionalidade excludente” (Ibid., p. 7), encontrando-se enraizado em nossa cultura e modo de produção, especialmente na educação escolar.

$\mathrm{Na}$ análise dos trabalhos de pesquisa encontrou-se quatro eixos que mostram, de forma múltipla, a variedade de objetos e modos de realização das pesquisas neste contexto. $\mathrm{O}$ primeiro eixo trata de pesquisas que centram sua atenção nos tempos-espaços no cotidiano. O segundo eixo aborda as pesquisas que discutem o ser pesquisador. O terceiro, aborda os modos de ser sujeito da educação especial e, o último eixo, centrará seu olhar nas investigações sobre o ser educador.

No primeiro eixo, que trata dos tempos-espaços no cotidiano da escola, o autor nos apresenta um tempo-espaço linear onde se confirma a homogeneização no espaço das escolas. Ainda, esse tempo no cotidiano das escolas pesquisadas mostra que a lógica fragmentária e o individualismo cartesiano parecem ser parte da maioria das escolas, embora essas pesquisas mostrem que um trabalho conjunto pode produzir mudanças extremamente significativas, não somente no processo de inclusão dos sujeitos da educação especial na escola de ensino regular, mas na própria estrutura das escolas em seu sentido mais global, superando a lógica excludente.

Outro achado nesse eixo aponta para trabalhos que mostram que o conhecimento produzido tanto pelo professor quanto pelo pesquisador deve se constituir em um conhecer que produza mudança, que aponte para outros caminhos. Outra pista importante que as dissertações e teses nos mostram é a multiplicidade de tempos-espaços de ensinar-aprender que se constituem de forma articulada, em um mesmo movimento. Ainda no primeiro eixo, as pesquisas abordam a forma como a escola deve ser reinventada para tornar-se um espaço de produção de novas formas de ser-saber a partir dos encontros com as diferenças para tornar-se, assim, um espaço inclusivo.

Todavia, a partir das pesquisas estudadas, Guimarães (2014) sugere que, para pensar a produção de uma outra educação pautada nos princípios da inclusão, é necessário fazermos um movimento profundamente "Heraclitidiano", ou seja, perceber como as tensões e as contradições são de importância crucial para compreendermos como a educação tem-se dado nesses espaços (Ibid., p. 125). E, nesse movimento, ampliar e afirmar a formação como uma prática "que vai se constituindo no tempo-espaço da própria escola que, nesse caso, se mescla ao próprio tempo-espaço de formação” (Ibid., p. 126).

Desse modo, vemos na tese de Guimarães (2014) um tratamento cuidadoso às análises apresentadas nas diversas pesquisas estudadas, segundo ele mesmo

poderíamos afirmar que estes trabalhos nos colocam o desafio de pensar tempoespaço como uma noção viva, dinâmica, contraditória, experiencial e criativa, especialmente porque as pesquisas nos revelam que a escola regular hoje, perpassada por movimentos antagônicos de inclusão e exclusão, necessita, para estar aberta as 
diferenças, constituir-se como tempo-espaço de formação, de criação e de reinvenção criativa impulsionada a partir dos novos saberes-fazeres que emergem de uma racionalidade existencializada que é produzida nos embates e nas tensões (Ibid., p. 135-136).

No segundo eixo de análise encontramos as considerações acerca do ser-pesquisador a partir de uma perspectiva do educar para e com as diferenças. As pesquisas estudadas destacam, também, que "o pesquisador do campo da educação [e] inclusão deve aprender a ser um aventureiro” (Ibid., p. 167). Ao longo das dissertações e teses, a coragem, audácia, curiosidade e solidariedade são algumas características que vão se perfilando para definir a atuação do pesquisador no contexto da EI.

No terceiro eixo traçado, Guimarães (2014) destaca que, ao pretender compreender como as pesquisas abordam os movimentos de constituição do ser-sujeito da Educação Especial o intuito não era buscar alguma forma ou representação universal e/ou universalizante de quem seja esse pretenso sujeito da educação especial, mas, ao contrário, buscou perceber como esse “ser-sujeito” da educação se desvelava e era compreendido de forma múltipla ao longo das pesquisas analisadas. Em quase todos os trabalhos estudados o autor destaca que a deficiência é entendida como algo intrínseco ao sujeito da educação especial.

Ao longo das dissertações e teses, percebemos que é extremamente comum que os sujeitos da educação inclusiva sejam percebidos e qualificados tão somente a partir de suas deficiências. Trata-se aqui de um processo identitário marcado pela estigmatização e pela produção de rótulo que levam muitas vezes a uma total negação de uma existência totalizante desses sujeitos, fadando-os ao isolamento e ao fracasso - tanto deles quanto da escola em sua função básica de ensino-aprendizado. Devemos destacar ainda que, ao serem colocados nesse lugar parece haver, como indicam as pesquisas, um processo de naturalização da ideia de que esses alunos ocupam o espaço de um suposto não-saber, que eles não conseguem aprender por sua suposta "natureza” fundada em sua deficiência (Ibid., p. 183).

Um outro processo que aparece nas pesquisas quando tratam o estudante da educação especial e que, na verdade, está intrinsecamente ligado ao aspecto acima mencionado, tratase do processo de invisibilidade ao qual os estudantes da educação especial são destinados nas escolas estudadas. Se a exclusão e o preconceito podem se dar por meio de palavras, ações ou gestos, encontramos no cotidiano das escolas, "uma refinada e eficiente forma de exclusão que é a de simplesmente não notar a existência ou as necessidades desses sujeitos" (Ibid., p. 185). Nesse sentido, as pesquisas evidenciam a produção de uma exclusão marcada pelo silêncio, “encobrindo a presença de sujeitos que se tornam invisíveis [...] 'desaparecem' em meio a seu próprio silêncio” (Ibid., p. 185).

Ainda no eixo três, a análise das pesquisas mostra que em quase todas as investigações comparece a visão médico-clínica nas práticas que se dão no espaço escolar. Chama-nos a atenção a forma como esse modelo de explicação da realidade encontra-se extremamente propagado, tanto nos discursos quanto nas ações que perpassam o cotidiano das escolas regulares ao buscarem lidar com os sujeitos com deficiência. 
[...] tanto a concepção da deficiência como algo intrínseco ao sujeito especial, quanto a invisibilidade desses sujeitos e a forte marca da padronização médico-clínica a que estão submetidos, [...] estão profundamente inter-relacionados a um dado modelo de racionalidade que é regido por princípios como o princípio da adequação e da impessoalidade que revelam, na verdade, o próprio sentido "impropriedade" da existência [...] Estamos lançados em uma racionalidade excludente e fria, mas esperando dela o calor e o aconchego de uma racionalidade inclusiva e aberta - eis, talvez, o maior de todos os paradoxos que podemos constatar em nossa pesquisa (Ibid., p. 191).

Finalmente, o quarto eixo do trabalho de Guimarães (2014) aborda o ser-educador a partir de uma perspectiva inclusiva.

Ao longo dos trabalhos de pesquisas materializados nas dissertações e teses com as quais o pesquisador dialogou, o educador também aparece como alguém que "deve se reinventar nesse processo, devendo fazer de seu ofício, invenção e criação a partir das contradições entre inclusão-exclusão que vão se desvelando ao longo de seu trabalho” (Ibid., p. 205). Nesse sentido, é necessário que haja uma alteração radical em relação à educação que temos hoje e, em sua maioria, os trabalhos recomendam a "mudança radical”, o que chama a atenção de Guimarães (2014) para algo de grande importância que é a necessidade da mudança se fazer presente em todos os setores e segmentos da educação e da prática social. As dissertações e teses analisadas pelo pesquisador, em sua maioria, dão grande destaque às práticas pedagógicas tentando compreender como elas podem provocar e potencializar essas mudanças.

Guimarães (2014) ainda mostra que, ao longo dos trabalhos de pesquisa, a questão da experimentação, da busca de se criar novas formas de ensinar-aprender foi uma constante significativa.

[...] novas questões foram emergindo [...] ligados ao mundo vivido-compartilhado dos sujeitos que aí se encontram, se interrogam e se questionam. A lógica dos encontros com esses sujeitos, como apontam as pesquisas, parecem estar ligadas à lógica da auto-interrogação, do auto-questionamento, que se percebe sempre no limite de uma práxis existencial marcada por um ainda-não que nos conclama a um poder-se-fazer, sempre permeada nesse espaço com o outro, que muitas vezes mais nos interroga do que nos responde (Ibid., p. 209).

Assim, as análises das pesquisas mostram que um dos maiores desafios lançados ao educador que atua neste contexto de EI é reconstruir-se constantemente, reinventar-se a partir de encontro aberto junto às diferenças, "valorizando os saberes-fazeres a partir de uma racionalidade colaborativa que tem como grande desafio ultrapassar a forte herança deixada pelo tecnicismo e que ainda encontra raízes fortes do espaço das escolas e nas relações aí estabelecidas” (Ibid., p. 218). 
Finalmente queremos destacar uma última contribuição apresentada na tese aqui tratada e que enfoca nas pesquisas outras possibilidades de saberes e fazeres que reinventam o conhecimento e que, desse modo, reinventam a própria vida.

\section{Provisórias conclusões}

Iniciamos a escrita deste artigo instigadas pela questão colocada por Artiles (2018) que inclusão na educação? Buscamos, em âmbito nacional e local, trabalhos científicos que abordam a EI como foco de atenção em suas pesquisas. Nesse processo, as pistas encontradas colaboram para colocar alguns elementos significativos na direção de responder a provocação inicial.

Tendo como referência teórico-epistemológica a abordagem pluralista do campo das políticas públicas, buscamos explicitar e compor com as aproximações e estranhamentos quanto à compreensão da EI de pesquisadores brasileiros em diálogo com Artiles (2018). Os tensionamentos em torno das concepções expressas reafirmam a ambiguidade e fragilidade do conceito e alertam para a necessidade de se atentar para o estreitamento da EI à educação especial, o que se observa tanto nos Estados Unidos quanto no Brasil. Em face deste estreitamento, novas exclusões seguem sendo gestadas no âmbito das práticas políticas de discriminação e invisibilidade das questões de gênero, raça e classe no atravessamento das pesquisas e práticas. Dentre as exclusões, o desafio para as pesquisas de pautar, na educação de jovens e adultos, estudos sobre o que Artiles (2018) denomina dimensão subjetiva da deficiência.

De forma ampla, os trabalhos de pesquisa no estado do Espírito Santo têm-se perfilado no interesse em compreender a realidade local criando, para isso, processos e dispositivos metodológicos de forma a intervir no próprio cotidiano escolar inclusivo. Para Guimarães (2014) "temos, portanto, indícios de um movimento metodológico e epistemológico que reflete os trabalhos sobre educação inclusiva no âmbito do PPGE-UFES, que aponta para um fazer-pesquisa no qual vemos um questionamento radical de uma perspectiva cartesiana e/ou positivista do modo de se fazer ciência” (Ibid., p. 157).

Nas pesquisas realizadas nos últimos vinte anos no âmbito da EI, aparece uma constante interrogação dos dualismos que dicotomizam a realidade na realização das pesquisas, separando sujeito $\mathrm{X}$ objeto, pesquisador $\mathrm{X}$ sujeito da pesquisa. Assim, encontramos um grande número de investigações orientadas pelos princípios metodológicos da pesquisa-ação no intuito de acompanhar processos e movimentos dos saberes-fazeres no cotidiano das escolas que foram alvo de estudos em nível de mestrado e doutorado.

Paradoxalmente, nas análises da tese pesquisada, encontramos pistas que confirmam práticas nas escolas do ES de negação do espaço de criação coletiva quando comparece a busca de ações que, antecipadamente, respondam à ansiedade e "angústia do novo, do diferente, buscando assim distanciar-se de qualquer ameaça de incerteza” (Ibid., p. 214). 
Para Artiles (2018) uma das forças que tem dificultado a expansão da EI é a natureza daltônica das pesquisas e práticas no cotidiano escolar que, conjuntamente com o retorno da tecnocracia “mantém a atenção da EI para sistemas de suporte. Guimarães (2014) coloca que

as pesquisas nos revelam, um processo de negação do espaço da criação-colaborativa, já que o tecnicismo se apoia em receituários e hierarquias já bem definidas embora suas promessas fazem mais camuflar do que enfrentar uma dada realidade. As pesquisas indicam, inclusive, o grande risco de naturalização da ideia de possíveis desvios e patologias que, longe de serem processos naturais, são produções históricas e culturais (Ibid., p. 216).

Nesse sentido, e como confirmado também por Artiles (2018), as pesquisas têm contribuído para a construção de conhecimentos e têm avançado na análise de programas de equidade mas que, de modo contrário, “falham em atentar à contextos locais e históricos [...] O resultado final é a perpetuação de discursos fragmentados que colidem com a equidade educacional” (Ibid., p. 4).

Nesse horizonte, a tese de Guimarães (2014) comparece como uma significativa contribuição uma vez que o autor mostra como é importante realizar trabalhos investigativos que assumam o tempo-espaço vivo, dinâmico, contraditório, experiencial e criativo

Desse modo, entendemos que um dos direcionamentos pautados nas pesquisas para futuros trabalhos apontam para formas de realização de estudos que possibilitem a abertura para a realização e criação de uma racionalidade colaborativa, inclusiva e aberta, necessária e urgente na produção da realidade.

\section{Notas}

1. Em relação ao acesso à escola, os dados censitários de 2012 registram “105.246 matrículas de alunos com necessidades educacionais especiais na Educação de Jovens e Adultos (EJA), sendo 47,69\% matriculados no ensino regular e 52,31\% no ensino especial” (MELLETI, 2014, p. 803).

2. Conceito trabalhado por Lyotard (1988), que faz crítica ao que denomina visões totalizantes da história.

3. Esses movimentos ficaram conhecidos como Disability Rights Movement.

4. Gaudenzi e Ortega (2016) abordam uma série de estudos realizados nos países anglo-saxônicos conhecidos pelo termo Disability Studies que colaboram para pensar a opressão social da pessoa com deficiência. Devemos destacar, também, a contribuição dos estudos feministas que têm colaborado, em um segundo momento, com análises a respeito da construção cultural da normalidade, chegando a afirmar que o que oprime é a cultura da normalidade que coloca a deficiência como indesejável.

\section{Referências}


ARTILES, A. Que inclusão e que diversidade na educação. In: Seminário Internacional para que cidadania? Promessas, perguntas e propostas que interrogam equidade, inclusão e diversidade. Campus Nova Iguaçú, de 10 a 14 de setembro na Universidade Federal Rural do Rio de Janeiro/UFRRJ em 2018.

BRASIL. Declaração de Salamanca: recomendações para a construção de uma escola inclusiva. Brasília: MEC/Secretaria de Educação Especial, 2003.

BUENO, J. G. S. A. inclusão de alunos deficientes nas classes comuns do ensino regular. Temas sobre desenvolvimento, São Paulo, vol. 9, n. 54, 2001.

CELlARD, A. A análise documental. In: POUPART, J. et al. A pesquisa qualitativa: enfoques epistemológicos e metodológicos. Petrópolis: Vozes, 2008. pp. 295-316.

DICIONÁRIO PRIBERAM DA LÍNGUA PORTUGUESA. Disponível em: https://dicionario.priberam.org/discromatopsia. Acesso em: 14 de março de 2019.

DINIZ, D. O que é deficiência. São Paulo: Editora Brasiliense: 2007.

FOUCAULT, M. Arqueologia do saber. Rio de Janeiro: Martins Fontes, 2005.

GAUDENZI, P.; ORTEGA, F. Problematizando o conceito de deficiência a partir das noções de autonomia e normalidade. Revista Ciência e saúde coletiva. Deficiência, família e sociedade. Rio de Janeiro: Associação Brasileira de saúde coletiva, Vol. 21, nº 10, de outubro de 2016, pp. 3061-3070.

GUIMARÃES, A. S. Crítica da razão excludente: desvelando novas racionalidades a partir de pesquisas em Educação especial numa perspectiva inclusiva. Tese (doutorado). Programa de Pós-graduação em Educação. Universidade Federal do Espírito Santo, 2014, (mimeo).

LASTA, L. L.; HILLESHEIM, B. Educação para todos e educação inclusiva: alguns apontamentos. Revista Teoria e Prática da Educação. V. 15, nº 2, pp. 59-73, maio a agosto de 2012.

LOPES, M. C. Inclusão Escolar: Currículo, diferença e identidade. In: LOPES, Maura Corcini; DAL'IGNA, Maria Claudia (Org.). In/Exclusão: nas tramas da escola. Canoas: Ulbra, 2007. pp. 11-33.

LYOTARD, J. F. O pós-moderno. Rio de Janeiro: José Olympio, 1988.

MAINARDES, J. A pesquisa no campo da política educacional: perspectivas teórico-epistemológicas e o lugar do pluralismo. Revista Brasileira de Educação. Rio de Janeiro: Anped, vol. 23, 2018.

MELETTI, S. M. F. Indicadores Educacionais sobre a Educação Especial no Brasil e no Paraná. Educação e Realidade, Porto Alegre, v. 39, n. 3, p. 789-809, jul./set. 2014 . Disponível em: http://www.ufrgs.br/edu_realidade. Acesso em: 14 de março de 2019.

MORAES, M.; KASTRUP, V. Exercícios de ver e não ver: arte e pesquisa COM pessoas com deficiência visual. Rio de Janeiro: Nau, 2010.

PADILHA, A. M. L.; OLIVEIRA, I. M. (Orgs). Educação para todos: as muitas faces da inclusão escolar. Campinas, SP: Papirus, 2013.

VARELA F.; THOMPSON, E.; ROSCH, E. De Cuerpo presente: las ciencias cognitivas y la experiencia humana. $1^{\text {a }}$ edição. Barcelona: Editora Gedisa, 1992.

VEIGA-NETO, A.; LOPES, M. C. Inclusão, exclusão, in/exclusão. Verve, 20: 121-135, 2011.

\section{Correspondência}

Edna Castro de Oliveira: Professora da Universidade Federal do Espírito Santo.

E-mail: oliveiraedna@yahoo.com.br

Marcia Roxana Cruces Cuevas: Professora da Universidade Federal do Espírito Santo.

E-mail: marcia.roxana@hotmail.com 
Texto publicado em Currículo sem Fronteiras com autorização da autora. 